OPEN ACCESS

Edited by

Daniel Johnston,

University of Texas at Austin, USA

Reviewed by:

Lucy Maree Palmer

University of Bern, Switzerland

Rishikesh Narayanan

Indian Institute of Science, India

Brian Kalmbach,

Allen Institute for Brain Science, USA

*Correspondence:

Satoshi Manita

smanita@yamanashi.ac.jp

Masanori Murayama

masa_murayama@brain.riken.jp

Received: 24 November 2016 Accepted: 31 January 2017 Published: 15 February 2017

Citation:

Manita S, Miyakawa H, Kitamura K and Murayama M (2017) Dendritic Spikes in Sensory Perception.

Front. Cell. Neurosci. 11:29. doi: 10.3389/fncel.2017.00029

\section{Dendritic Spikes in Sensory Perception}

\author{
Satoshi Manita ${ }^{1,2 *}$, Hiroyoshi Miyakawa ${ }^{3}$, Kazuo Kitamura $^{2}$ and Masanori Murayama ${ }^{1 *}$ \\ ${ }^{1}$ Laboratory for Behavioral Neurophysiology, Brain Science Institute, RIKEN, Wako City, Saitama, Japan, ${ }^{2}$ Department \\ of Neurophysiology, Division of Medicine, University of Yamanashi, Chuo-shi, Japan, ${ }^{3}$ Laboratory of Cellular Neurobiology, \\ Tokyo University of Pharmacy and Life Sciences, Hachioji, Japan
}

What is the function of dendritic spikes? One might argue that they provide conditions for neuronal plasticity or that they are essential for neural computation. However, despite a long history of dendritic research, the physiological relevance of dendritic spikes in brain function remains unknown. This could stem from the fact that most studies on dendrites have been performed in vitro. Fortunately, the emergence of novel techniques such as improved two-photon microscopy, genetically encoded calcium indicators (GECls), and optogenetic tools has provided the means for vital breakthroughs in in vivo dendritic research. These technologies enable the investigation of the functions of dendritic spikes in behaving animals, and thus, help uncover the causal relationship between dendritic spikes, and sensory information processing and synaptic plasticity. Understanding the roles of dendritic spikes in brain function would provide mechanistic insight into the relationship between the brain and the mind. In this review article, we summarize the results of studies on dendritic spikes from a historical perspective and discuss the recent advances in our understanding of the role of dendritic spikes in sensory perception.

Keywords: dendritic spike, sensory perception, dendritic integration, pyramidal neuron, neocortex, top-down control, bottom-up processing

\section{A HISTORICAL PERSPECTIVE OF DENDRITIC SPIKE STUDIES}

Early in vivo studies in the 1950s suggested that spikes evoked near the soma propagate into dendrites (Chang, 1951; Bishop and Clare, 1953; Fatt, 1957a,b; Eccles et al., 1958; Terzuolo and Araki, 1961). Results of some studies also suggested that spikes are locally initiated at dendrites before the generation of somatic action potentials (Cragg and Hamlyn, 1955; Andersen, 1960; Spencer and Kandel, 1961; Fujita and Sakata, 1962). These ideas were supported by intracellular sharp electrode recordings from the dendrites of several types of neurons (Cragg and Hamlyn, 1955; Andersen, 1960; Fujita and Sakata, 1962; Llinás and Nicholson, 1971; Wong et al., 1979). Subsequent studies also investigated the electrical properties of dendrites by performing whole-cell recordings in brain slices (Stuart et al., 1993; Stuart and Sakmann, 1994; Spruston et al., 1995; Magee and Johnston, 1997). These studies demonstrated that backwardpropagating spikes (backpropagating action potential, BPAP) from the soma are $\mathrm{Na}^{+}$spikes. Studies conducted more recently showed that $\mathrm{Na}^{+}$spikes can be locally initiated in dendrites in response to synaptic inputs, before the initiation of somatic spikes (Kim and Connors, 1993; Stuart et al., 1997; Golding and Spruston, 1998; Ariav et al., 2003; Gasparini et al., 2004; Gasparini and Magee, 2006; Losonczy and Magee, 2006; Nevian et al., 2007). In vitro studies identified dendritic spikes in various types of neurons, and showed that these dendritic spikes are mediated by voltage-gated $\mathrm{Ca}^{2+}$ channels ( $\mathrm{Ca}^{2+}$ spikes) or $\mathrm{N}$-methyl-D-aspartate (NMDA) receptor channels 
(NMDA spikes; see reviews, Larkum and Nevian, 2008; Antic et al., 2010; Major et al., 2013). Taken together, these extensive in vitro studies have revealed unique electrical properties of dendrites, either passive or active, that enable neurons to output spikes by integrating synaptic inputs in various ways. These studies stimulated dendritic research aimed at understanding the physiological functions of dendritic spikes.

Why do dendrites have spikes? It is reasonable to assume that dendritic spikes have physiological functions for neuronal computation and synaptic plasticity in single neurons and circuits (Poirazi and Mel, 2000; London and Häusser, 2005). Dendritic $\mathrm{Ca}^{2+}$ spikes can trigger somatic repetitive action potentials (Connors and Gutnick, 1990; Amitai et al., 1993; Kim and Connors, 1993; Schiller et al., 1997; Helmchen et al., 1999; Larkum et al., 1999; Larkum and Zhu, 2002). Multiple NMDA spikes trigger a dendritic $\mathrm{Ca}^{2+}$ spike, which can induce somatic burst firing; however, a single NMDA spike cannot trigger a somatic action potential or can trigger only a single action potential (Milojkovic et al., 2004; Polsky et al., 2004, 2009; Larkum et al., 2009; Lavzin et al., 2012; Palmer et al., 2014). These dendritic spikes increase intracellular concentrations of $\mathrm{Ca}^{2+}$, which acts as a second messenger in cells and induces synaptic plasticity (note that plasticity such as long-term potentiation that does not depend on dendritic spikes has also been reported, Dudman et al., 2007), resulting in modification of somatic firings (Golding et al., 2002; Holthoff et al., 2006; Kampa et al., 2007; Johnston and Narayanan, 2008; Losonczy et al., 2008; Sjöström et al., 2008; Spruston, 2008; Takahashi and Magee, 2009; Kim et al., 2015; Basu et al., 2016). Because somatic spikes have been considered as a basic unit of information in the brain, dendritic spikes likely play an important role in information processing in the brain. In addition, the occurrence of dendritic spikes is controlled by various mechanisms such as spatiotemporal patterns of synaptic inputs (Gasparini et al., 2004; Gasparini and Magee, 2006; Losonczy and Magee, 2006; Branco and Häusser, 2010) and inhibitory synaptic inputs (Pérez-Garci et al., 2006; Murayama et al., 2009; Palmer et al., 2012). Therefore, dendritic spikes should increase the computational power of the system.

Several aspects of dendritic spikes, such as the cellular mechanisms underlying their generation and their contribution to computation in a single neuron and neural circuits, have been extensively investigated. However, little is known about the functional relevance of dendritic spikes in perception, which was one of the original and fundamental questions raised 50 years ago, when the existence of dendritic spikes was proposed (Spencer and Kandel, 1961; Llinás et al., 1968). In the last two decades, technical advances, such as two-photon microscopy, genetically encoded $\mathrm{Ca}^{2+}$ indicators (GECIs), and transgenic animals, have enabled researchers to examine dendritic activities in conjunction with animal behavior. Furthermore, neural activities can be manipulated using optogenetic methods with high spatiotemporal resolution. Emerging lines of evidence generated using these state-ofthe-art technologies have shown the physiological importance of dendritic spikes. Comprehensive reviews of dendritic mechanisms for synaptic integration and plasticity in vivo have been published recently (Grienberger et al., 2015; Stuart and Spruston, 2015; Palmer et al., 2016). In this review article, we summarize recent advances in elucidating not only the relationship between dendritic spikes and perception but also their causal relationship, focusing on $\mathrm{Ca}^{2+}$ and NMDA spikes in pyramidal neurons.

\section{ARE DENDRITIC SPIKES NECESSARY FOR PERCEPTION?}

\section{$\mathrm{Ca}^{2+}$ Spikes}

Previous studies in awake monkeys revealed that somatosensory stimulation induces a surface potential on electroencephalogram (EEG), termed "somatosensory evoked potential (SEP)", which represents the responses of a population of neurons in the sensory cortex (Cauller and Kulics, 1991). SEP consists of early and late components: a primary surface-positive component (P1) and a secondary surface-negative component (N1). The early component correlates with external information such as stimulus intensity, whereas the late component represents behaviors that require perception of the stimulation (Figure 1A; Kulics et al., 1977; Kulics, 1982; Cauller and Kulics, 1988, 1991; Cauller, 1995). The late components evoked by sensory stimulation have also been observed in dendrites during $\mathrm{Ca}^{2+}$ imaging of the rat S1 (Murayama and Larkum, 2009), and in other sensory areas of mammals via different recording techniques such as EEG, local field potential (LFP), and unitrecordings. These late components appear to be involved in perception (Lamme, 2001; Supèr et al., 2001; Del Cul et al., 2007; Meyer, 2011). Cauller (1995) hypothesized that the late component is mediated by dendritic spikes evoked by top-down inputs from higher-order brain areas such as the prefrontal cortex to the sensory area. However, no direct evidence has been obtained to prove this hypothesis. We recently investigated neural mechanisms underlying the late component of SEP, and reported that dendritic $\mathrm{Ca}^{2+}$ spikes in layer (L) 5 pyramidal neurons in the somatosensory cortex are involved in evoking this late component (Manita et al., 2015).

In our previous study (Manita et al., 2015), we used multi-unit recording (MUR) and LFP recording to measure neural activities evoked by hindpaw stimulation in the primary somatosensory cortex (S1) of mice. We identified early and late components similar to the two components of SEP in monkeys (Kulics et al., 1977; Kulics, 1982; Cauller and Kulics, 1988, 1991; Cauller, 1995). We showed that the early component is evoked by sensory inputs from the thalamus carrying information of hindpaw stimulation, and that this component activates the secondary motor cortex (M2), which is one of the higher-order brain areas. The late component was due to "top-down" feedback input from M2. Our viral tracing studies revealed that M2 neurons send their axons back to the S1 area, thus forming a reverberating circuit. The axons from M2 form synaptic contacts with both apical and basal dendrites of L5 pyramidal cells in S1 (Figure 1B). 

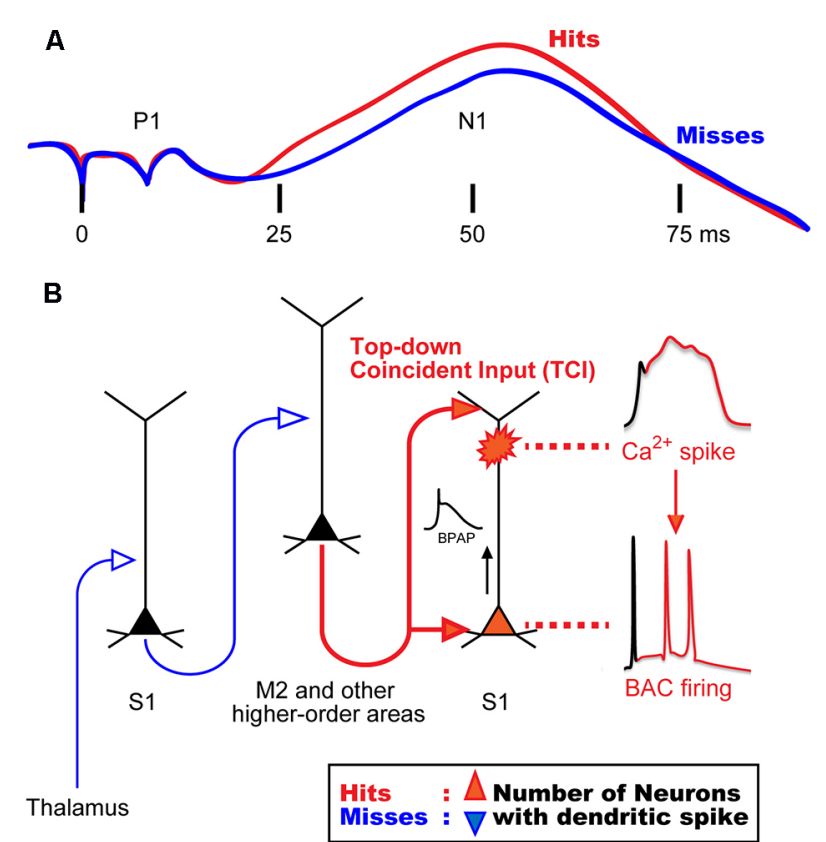

FIGURE 1 | Hypothetical model for mechanisms of sensory perception. (A) Animal perception, assumed by behavioral responses (i.e., hit or miss behaviors), correlates with the late component in a stimulus intensity discrimination task. Even though the intensity of sensory stimulation was identical, animal behavior responses were different and perceptual behaviors correlated with the late neural activities. (B) A novel mechanism for the late activity. Top-down inputs (here from M2) propagate from the bottom to the top layers of the sensory cortex in a short time window to reliably drive dendritic spiking and BAC firing ( $\sim 50 \mathrm{~ms}$ in $\mathbf{A}$ ). We termed this top-down input pattern, "top-down coincident input or TCl". We hypothesized that the number of neurons that had a $\mathrm{Ca}^{2+}$ spike during perception (Hits) behavior is larger than that during no perception (Misses). BAC, backpropagating action-potential-activated calcium spike; BPAP, backpropagating action potential. Panel (A) is reprinted with permission from Cauller (1995).

While the late component of the LFP is considered to be due to synaptic inputs from M2, the late component of MUR represents burst firing of somatic fast $\mathrm{Na}^{+}$spikes that are sustained for a short period. Therefore, a mechanism must exist by which the synaptic inputs from $\mathrm{M} 2$ to the apical and basal dendrites give rise to burst firing at the soma.

Previous in vitro and simulation studies showed that the dendritic $\mathrm{Ca}^{2+}$ spike in L5 pyramidal neurons is induced by pairing of subthreshold depolarizations of distal apical dendrites and BPAPs, which can be evoked by synaptic inputs to tuft and proximal dendrites, respectively (Larkum et al., 1999; Xu et al., 2012; Larkum, 2013; Shai et al., 2015). Larkum et al. (1999) named these dendritic $\mathrm{Ca}^{2+}$ spikes as backpropagating actionpotential-activated calcium spikes (BACs), and the resulting somatic burst firings as BAC firings.

In our study (Manita et al., 2015), current source density analysis of LFP using a linear probe showed that M2 top-down inputs coincidentally arrive at deep and superficial layers in S1 where basal and distal dendrites of L5 neurons located, respectively. By using two-photon microscopy and GECI,
G-CaMP7 (Sato et al., 2015), we showed that M2 inputs evoke BACs in the dendrites of L5 neurons in the S1. Next, we expressed archaerhodopsin (ArchT; Han et al., 2011) in M2 neurons and optically inhibited axon terminals of M2 neurons extending to S1. The inhibition of the top-down signal from M2 to S1 decreased somatic firings of L5 neurons in the S1 during the late component. We hypothesized that the firing was due to BACs because pharmacological inactivation of M2 activity resulted in blockade of dendritic $\mathrm{Ca}^{2+}$ spikes and somatic firing. Furthermore, optical inhibition of this top-down signal impaired the ability of mice to discriminate surface textures (e.g., smooth and rough textures). Taken together, these results suggest that dendritic spikes are critical and necessary for sensory perception.

Supporting this idea, a recent study showed that the appearance of dendritic $\mathrm{Ca}^{2+}$ spikes in L5 pyramidal neurons of S1 is correlated with perception in mice (Takahashi et al., 2016). In that study, dendritic $\mathrm{Ca}^{2+}$ spikes were measured during a perceptual detection task with whisker stimulation. The authors showed that a group of dendritic $\mathrm{Ca}^{2+}$ spikes and the resulting somatic firings are related to "hit" trials (i.e., perception of whisker stimulation) in mouse behavior. To investigate whether the dendritic $\mathrm{Ca}^{2+}$ activity causes mice perceptual behavior, they inhibited or activated dendritic activity by using a pharmacological agent or optogenetic manipulations. The inhibition or activation of dendritic activity decreased or increased the detection probability of the mice, respectively. These results demonstrated that the dendritic $\mathrm{Ca}^{2+}$ spike is causally related to perceptual decision in mice. Although further investigation will be needed to support the hypothesis that dendritic spikes represent the neural correlates of perception, the experimental data of this study are consistent with this hypothesis.

Larkum (2013) proposed that BAC firing requires the cell to receive inputs from both bottom-up and top-down pathways, and that these inputs need to coincide within a narrow window of time. In our study (Manita et al., 2015), however, because the delay between the bottom-up input (early component) and the top-down input (late component) was too long, the coincidence would not occur. We hypothesize that the somatic burst firing during the late component is due to BAC in the dendrites, and that BAC is evoked by the coincidence of the two separate synaptic contacts onto the basal and apical dendrites sent from M2 alone, not due to the coincidence of M2 input with thalamic inputs. This mechanism is possible because the top-down projection from M2 to lower and upper layers in S1 allows M2 neurons alone to generate coincident inputs onto separate parts of the dendrites of S1 neurons. We have named this type of input pattern "top-down coincident input (TCI)" to directly define the role of top-down input in the generation of dendritic spikes. Regarding conventional top-down control system (Gilbert and Sigman, 2007; Gilbert and Burgess, 2008), sensory neurons may combine bottom-up and top-down inputs to induce BAC firing, as suggested by Larkum (2013).

The brain may utilize similar top-down inputs, that we described (Manita et al., 2015), from parts of the brains 
other than M2 to generate the BAC and hence the late components for perception. Moreover, the TCI per se would enable sensory perception without inputs from the other areas of the brain responsible for higher functions such as attention and motivation, or even without sensory information. TCI without external sensory inputs would be related to the phenomenon of hallucination (or illusion), a perceptual experience without sensory stimulation. A previous human study has shown that besides S1, premotor and prefrontal cortices are activated during illusory perception (Blankenburg et al., 2006). Some patients with non-convulsive status epilepticus of frontal origin have reported somatic hallucinations. Single-photon emission computed tomography (SPECT) during somatic hallucinations showed activation not only in the frontal area but also in the parietal area, including S1 as the projected regions (Takaya et al., 2005). In addition, Powers et al. (2016) discussed that hallucinations are involved in top-down processes. We hypothesize that, in some pathological states (e.g., epilepsy), TCI even without sensory input causes BAC firing, resulting in somatic hallucination.

Several input pathways to S1 are considered to be involved in the generation of dendritic $\mathrm{Ca}^{2+}$ spikes. Xu et al. (2012) reported that inputs from the vibrissal motor cortex (vM1) combined with thalamic inputs induce dendritic $\mathrm{Ca}^{2+}$ spikes in the barrel cortex during active touch by whiskers (i.e., whisking behavior), suggesting that spike generation requires both sensory and motor information. Such dendritic $\mathrm{Ca}^{2+}$ spikes induced by the combination of inputs from different pathways likely have different physiological roles from those of spikes induced by each input pathway. For example, the $\mathrm{Ca}^{2+}$ spikes that Xu et al. (2012) reported may carry motor information from the whiskers as well as information of touch perception.

\section{NMDA Spikes}

Although it has been reported that induction of dendritic NMDA spikes require spatially and temporally clustered synaptic inputs, a previous simulation study has shown that in vivo-like background inputs lower the threshold for dendritic NMDA spikes without the clustered inputs and increase the efficacy of NMDA spikes to generate somatic spikes (Farinella et al., 2014). These results suggest that dendritic NMDA spikes have a greater impact on somatic spikes than that would be expected from the results of previous in vitro studies. Several studies have shown that whisker deflections induce NMDA-dependent depolarizations, presumably due to dendritic NMDA spikes in L 2/3 and 4 neurons, and that the spikes amplify thalamic inputs and determine somatic spiking (Lavzin et al., 2012; Gambino et al., 2014). In addition to whisker systems, studies on hindpaw somatosensory and visual systems have shown that dendritic NMDA spikes and consequent somatic spikes are induced by stimuli in $\mathrm{L} 2 / 3$ neurons in mice (Smith et al., 2013; Palmer et al., 2014). Lavzin et al. (2012) and Smith et al. (2013) showed that NMDA spikes encode direction selectivity of whisker stimulation and orientation tuning of visual stimulation, respectively. Recently, it has been shown that orientation selective and spatially-clustered synaptic inputs correlate with the occurrence of dendritic $\mathrm{Ca}^{2+}$ events, which are presumably NMDA spikes in L 2/3 neurons of the visual cortex (Wilson et al., 2016), suggesting that the orientation tuning of somatic spikes are strongly influenced by that of dendritic spikes. Taken together, these results suggest that dendritic NMDA spikes are also critically important for cellular mechanisms of perception.

\section{Hippocampus: Perception of Space}

Several lines of evidence have shown that the perception of the location of an animal in the external environment is one of the most common brain functions (Moser et al., 2008). In the hippocampus, spatial information is likely encoded by the firing of dendritic spikes in CA1 pyramidal neurons. In this type of neuron, dendritic $\mathrm{Ca}^{2+}$ spikes (Kamondi et al., 1998) or NMDA-dependent $\mathrm{Ca}^{2+}$ spikes (Grienberger et al., 2014) contribute to the generation of complex spikes. Moreover, place cells fire complex spikes when animals are in the place field, as shown in studies using in vivo whole-cell techniques with freely moving mice (Epsztein et al., 2011) and head-restricted mice in a virtual-reality environment (Harvey et al., 2009). More recently, a two-photon imaging study in behaving mice (Sheffield and Dombeck, 2015) has directly shown the contribution of dendritic $\mathrm{Ca}^{2+}$ spikes to the representation of the place field in the dendrites of CA1 neurons. In addition to these studies, dendritic spikes induced by the integration of two different inputs from the entorhinal cortex and hippocampal CA3 region have been shown to increase both the place field firing rates and the appearance of complex spikes in CA1 pyramidal neurons (Bittner et al., 2015).

\section{CONCLUSION}

It has been postulated that the so-called "executive control system" is essential for perception, and that top-down control from this system that is responsible for higher brain functions modulates the activities of the primary sensory cortex in order to refine and define the sensory signal (Gilbert and Sigman, 2007; Gilbert and Burgess, 2008). This hypothesis seems to implicitly assume that there are specific brain regions dedicated to executing higher brain functions, and that the trains of impulses sent out along the axons of the neurons responsible for the executive control system constitute the basis for neuronal correlates of perception. In humans, the prefrontal cortex is thought to be responsible for the executive control system.

Results of the recent in vivo studies summarized in this review article indicate strong physiological relevance of dendritic spike generation in perception, and suggest that dendritic $\mathrm{Ca}^{2+}$ spikes and NMDA spikes in the somatosensory and hippocampal cortex support not only neuronal plasticity, but also the computational aspect of neuronal activities. In S1 pyramidal cells, TCI from M2 evokes dendritic spikes and somatic firing (Manita et al., 2015), which constitutes the late component, a necessary condition for sensory perception. These findings imply that the activities of neurons in the primary sensory cortex are not secondary to the executive control system, but rather that they constitute an integral part of the executive control system. We hypothesize that dendritic $\mathrm{Ca}^{2+}$ spikes and NMDA spikes 
in the pyramidal cells of primary cortices are not only necessary but may also be sufficient for sensory perception. This may be the case for other brain functions as well since the axonal pattern of innervation, similar to the one from M2 to S1, is ubiquitous across the cerebrum (Rockland and Virga, 1989; Coogan and Burkhalter, 1990; Cauller et al., 1998). We propose that dendritic spikes occurring in various regions of the brain, including S1, are the basis of cognitive functions such as perception, motor planning, attention and even self-awareness.

Although dendritic activities in the primary sensory cortex may indicate the occurrence of sensory perception, the contents of the perceived information might be represented separately in a brain region other than the primary cortex, and the outputs from the primary cortex might need to be conveyed to those systems for the sensory information to be recognized. One of the most important questions that should be addressed in future studies is whether dendritic spikes in the primary sensory cortex are associated with mental representation of perception, or whether there are regions responsible for perception located elsewhere, downstream of the primary sensory cortex. Recent

\section{REFERENCES}

Amitai, Y., Friedman, A., Connors, B. W., and Gutnick, M. J. (1993). Regenerative activity in apical dendrites of pyramidal cells in neocortex. Cereb. Cortex 3 , 26-38. doi: 10.1093/cercor/3.1.26

Andersen, P. (1960). Interhippocampal impulses. II. Apical dendritic activation of CAI neurons. Acta Physiol. Scand. 48, 178-208. doi: 10.1111/j.1748-1716.1960. tb01856.x

Antic, S. D., Zhou, W. L., Moore, A. R., Short, S. M., and Ikonomu, K. D. (2010). The decade of the dendritic NMDA spike. J. Neurosci. Res. 88, 2991-3001. doi: 10.1002/jnr.22444

Ariav, G., Polsky, A., and Schiller, J. (2003). Submillisecond precision of the inputoutput transformation function mediated by fast sodium dendritic spikes in basal dendrites of CA1 pyramidal neurons. J. Neurosci. 23, 7750-7758.

Basu, J., Zaremba, J. D., Cheung, S. K., Hitti, F. L., Zemelman, B. V., Losonczy, A., et al. (2016). Gating of hippocampal activity, plasticity, and memory by entorhinal cortex long-range inhibition. Science 351:aaa5694. doi: $10.1126 /$ science.aaa5694

Bishop, G. H., and Clare, M. H. (1953). Responses of cortex to direct electrical stimuli applied at different depths. J. Neurophysiol. 16, 1-19.

Bittner, K. C., Grienberger, C., Vaidya, S. P., Milstein, A. D., Macklin, J. J., Suh, J., et al. (2015). Conjunctive input processing drives feature selectivity in hippocampal CA1 neurons. Nat. Neurosci. 18, 1133-1142. doi: 10.1038/ nn. 4062

Blankenburg, F., Ruff, C. C., Deichmann, R., Rees, G., and Driver, J. (2006). The cutaneous rabbit illusion affects human primary sensory cortex somatotopically. PLoS Biol. 4:e69. doi: 10.1371/journal.pbio.0040069

Branco, T., and Häusser, M. (2010). The single dendritic branch as a fundamental functional unit in the nervous system. Curr. Opin. Neurobiol. 20, 494-502. doi: 10.1016/j.conb.2010.07.009

Cauller, L. (1995). Layer I of primary sensory neocortex: where top-down converges upon bottom-up. Behav. Brain Res. 71, 163-170. doi: 10.1016/01664328(95)00032-1

Cauller, L. J., Clancy, B., and Connors, B. W. (1998). Backward cortical projections to primary somatosensory cortex in rats extend long horizontal axons in layer I. J. Comp. Neurol. 390, 297-310. doi: 10.1002/(SICI)10969861(19980112)390:2<297::AID-CNE11>3.3.CO;2-0

Cauller, L. J., and Kulics, A. T. (1988). A comparison of awake and sleeping cortical states by analysis of the somatosensory-evoked response of postcentral area 1 in rhesus monkey. Exp. Brain Res. 72, 584-592. doi: 10.1007/bf00250603

Cauller, L. J., and Kulics, A. T. (1991). The neural basis of the behaviorally relevant $\mathrm{N} 1$ component of the somatosensory-evoked potential in SI cortex of awake technical advances allow researchers to study neuronal activities during behavioral tasks, and are beginning to provide clues to elucidate the mechanisms underlying the mind-body problem. To further our understanding of this issue, we need to study the dynamic coordination of neuronal activities, particularly dendritic activities, of populations of various neuron types, distributed across various parts of the brain.

\section{AUTHOR CONTRIBUTIONS}

All authors wrote the initial draft of the manuscript, and critically reviewed the manuscript. The final version of the manuscript was approved by all authors.

\section{ACKNOWLEDGMENTS}

MM acknowledges support from a Grant-in-Aid for Young Scientists (A) from the Japan Society for the Promotion of Science (JSPS) and the Uehara Memorial Foundation.

monkeys: evidence that backward cortical projections signal conscious touch sensation. Exp. Brain Res. 84, 607-619. doi: 10.1007/bf00230973

Chang, H. T. (1951). Dendritic potential of cortical neurons produced by direct electrical stimulation of the cerebral cortex. J. Neurophysiol. $14,1-21$.

Connors, B. W., and Gutnick, M. J. (1990). Intrinsic firing patterns of diverse neocortical neurons. Trends Neurosci. 13, 99-104. doi: 10.1016/01662236(90)90185-d

Coogan, T. A., and Burkhalter, A. (1990). Conserved patterns of cortico-cortical connections define areal hierarchy in rat visual cortex. Exp. Brain Res. 80, 49-53. doi: 10.1007/bf00228846

Cragg, B. G., and Hamlyn, L. H. (1955). Action potentials of the pyramidal neurones in the hippocampus of the rabbit. J. Physiol. 129, 608-627. doi: 10.1113/jphysiol.1955.sp005382

Del Cul, A., Baillet, S., and Dehaene, S. (2007). Brain dynamics underlying the nonlinear threshold for access to consciousness. PLoS Biol. 5:e260. doi: 10.1371/journal.pbio.0050260

Dudman, J. T., Tsay, D., and Siegelbaum, S. A. (2007). A role for synaptic inputs at distal dendrites: instructive signals for hippocampal long-term plasticity. Neuron 56, 866-879. doi: 10.1016/j.neuron.2007.10.020

Eccles, J. C., Libet, B., and Young, R. R. (1958). The behaviour of chromatolysed motoneurones studied by intracellular recording. J. Physiol. 143, 11-40. doi: 10.1113/jphysiol.1958.sp006041

Epsztein, J., Brecht, M., and Lee, A. K. (2011). Intracellular determinants of hippocampal CA1 place and silent cell activity in a novel environment. Neuron 70, 109-120. doi: 10.1016/j.neuron.2011.03.006

Farinella, M., Ruedt, D. T., Gleeson, P., Lanore, F., and Silver, A. R. (2014). Glutamate-bound NMDARs arising from in vivo-like network activity extend spatio-temporal integration in a L5 cortical pyramidal cell model. PLoS Comput. Biol. 10:e1003590. doi: 10.1371/journal.pcbi.1003590

Fatt, P. (1957a). Electric potentials occurring around a neurone during its antidromic activation. J. Neurophysiol. 20, 27-60.

Fatt, P. (1957b). Sequence of events in synaptic activation of a motoneurone. J. Neurophysiol. 20, 61-80.

Fujita, Y., and Sakata, H. (1962). Electrophysiological properties of CA1 and CA2 apical dendrites of rabbit hippocampus. J. Neurophysiol. 25, 209-222.

Gambino, F., Pagès, S., Kehayas, V., Baptista, D., Tatti, R., Carleton, A., et al. (2014). Sensory-evoked LTP driven by dendritic plateau potentials in vivo. Nature 515, 116-119. doi: 10.1038/nature13664

Gasparini, S., and Magee, J. C. (2006). State-dependent dendritic computation in hippocampal CA1 pyramidal neurons. J. Neurosci. 26, 2088-2100. doi: 10.1523/JNEUROSCI.4428-05.2006 
Gasparini, S., Migliore, M., and Magee, J. C. (2004). On the initiation and propagation of dendritic spikes in CA1 pyramidal neurons. J. Neurosci. 24, 11046-11056. doi: 10.1523/JNEUROSCI.2520-04.2004

Gilbert, S. J., and Burgess, P. W. (2008). Executive function. Curr. Biol. 18, R110-R114. doi: 10.1016/j.cub.2007.12.014

Gilbert, C. D., and Sigman, M. (2007). Brain states: top-down influences in sensory processing. Neuron 54, 677-696. doi: 10.1016/j.neuron.2007.05.019

Golding, N. L., and Spruston, N. (1998). Dendritic sodium spikes are variable triggers of axonal action potentials in hippocampal CA1 pyramidal neurons. Neuron 21, 1189-1200. doi: 10.1016/s0896-6273(00)80635-2

Golding, N. L., Staff, N. P., and Spruston, N. (2002). Dendritic spikes as a mechanism for cooperative long-term potentiation. Nature 418, 326-331. doi: $10.1038 /$ nature 00854

Grienberger, C., Chen, X., and Konnerth, A. (2014). NMDA receptor-dependent multidendrite $\mathrm{Ca}^{2+}$ spikes required for hippocampal burst firing in vivo. Neuron 81, 1274-1281. doi: 10.1016/j.neuron.2014.01.014

Grienberger, C., Chen, X., and Konnerth, A. (2015). Dendritic function in vivo. Trends Neurosci. 38, 45-54. doi: 10.1016/j.tins.2014.11.002

Han, X., Chow, B. Y., Zhou, H., Klapoetke, N. C., Chuong, A., Rajimehr, R., et al. (2011). A high-light sensitivity optical neural silencer: development and application to optogenetic control of non-human primate cortex. Front. Syst. Neurosci. 5:18. doi: 10.3389/fnsys.2011.00018

Harvey, C. D., Collman, F., Dombeck, D. A., and Tank, D. W. (2009). Intracellular dynamics of hippocampal place cells during virtual navigation. Nature 461, 941-946. doi: 10.1038/nature08499

Helmchen, F., Svoboda, K., Denk, W., and Tank, D. W. (1999). In vivo dendritic calcium dynamics in deep-layer cortical pyramidal neurons. Nat. Neurosci. 2, 989-996. doi: 10.1038/14788

Holthoff, K., Kovalchuk, Y., and Konnerth, A. (2006). Dendritic spikes and activity-dependent synaptic plasticity. Cell Tissue Res. 326, 369-377. doi: 10.1007/s00441-006-0263-8

Johnston, D., and Narayanan, R. (2008). Active dendrites: colorful wings of the mysterious butterflies. Trends Neurosci. 31, 309-316. doi: 10.1016/j.tins.2008. 03.004

Kamondi, A., Acsády, L., and Buzsáki, G. (1998). Dendritic spikes are enhanced by cooperative network activity in the intact hippocampus. J. Neurosci. 18, 3919-3928.

Kampa, B. M., Letzkus, J. J., and Stuart, G. J. (2007). Dendritic mechanisms controlling spike-timing-dependent synaptic plasticity. Trends Neurosci. 30, 456-463. doi: 10.1016/j.tins.2007.06.010

Kim, H. G., and Connors, B. W. (1993). Apical dendrites of the neocortex: correlation between sodium- and calcium-dependent spiking and pyramidal cell morphology. J. Neurosci. 13, 5301-5311.

Kim, Y., Hsu, C. L., Cembrowski, M. S., Mensh, B. D., and Spruston, N. (2015). Dendritic sodium spikes are required for long-term potentiation at distal synapses on hippocampal pyramidal neurons. Elife 4:e06414. doi: 10.7554/eLife.06414

Kulics, A. T. (1982). Cortical neural evoked correlates of somatosensory stimulus detection in the rhesus monkey. Electroencephalogr. Clin. Neurophysiol. 53, 78-93. doi: 10.1016/0013-4694(82)90108-0

Kulics, A. T., Lineberry, C. G., and Roppolo, J. R. (1977). Neurophysiological correlates of sensory discrimination performance to electrical cutaneous stimuli in rhesus monkey. Brain Res. 136, 360-365. doi: 10.1016/00068993(77)90811-3

Lamme, V. A. (2001). Blindsight: the role of feedforward and feedback corticocortical connections. Acta Psychol. (Amst) 107, 209-228. doi: 10.1016/s0001-6918(01)00020-8

Larkum, M. (2013). A cellular mechanism for cortical associations: an organizing principle for the cerebral cortex. Trends Neurosci. 36, 141-151. doi: 10.1016/j. tins.2012.11.006

Larkum, M. E., and Nevian, T. (2008). Synaptic clustering by dendritic signalling mechanisms. Curr. Opin. Neurobiol. 18, 321-331. doi: 10.1016/j.conb.2008. 08.013

Larkum, M. E., Nevian, T., Sandler, M., Polsky, A., and Schiller, J. (2009). Synaptic integration in tuft dendrites of layer 5 pyramidal neurons: a new unifying principle. Science 325, 756-760. doi: 10.1126/science.1171958

Larkum, M. E., and Zhu, J. J. (2002). Signaling of layer 1 and whisker-evoked $\mathrm{Ca}^{2+}$ and $\mathrm{Na}^{+}$action potentials in distal and terminal dendrites of rat neocortical pyramidal neurons in vitro and in vivo. J. Neurosci. 22, 6991-7005.
Larkum, M. E., Zhu, J. J., and Sakmann, B. (1999). A new cellular mechanism for coupling inputs arriving at different cortical layers. Nature 398, 338-341. doi: $10.1038 / 18686$

Lavzin, M., Rapoport, S., Polsky, A., Garion, L., and Schiller, J. (2012). Nonlinear dendritic processing determines angular tuning of barrel cortex neurons in vivo. Nature 490, 397-401. doi: 10.1038/nature11451

Llinás, R., and Nicholson, C. (1971). Electrophysiological properties of dendrites and somata in alligator Purkinje cells. J. Neurophysiol. 34, 532-551.

Llinás, R., Nicholson, C., Freeman, J. A., and Hillman, D. E. (1968). Dendritic spikes and their inhibition in alligator Purkinje cells. Science 160, 1132-1135. doi: $10.1126 /$ science.160.3832.1132

London, M., and Häusser, M. (2005). Dendritic computation. Annu. Rev. Neurosci. 28, 503-532. doi: 10.1146/annurev.neuro.28.061604.135703

Losonczy, A., and Magee, J. C. (2006). Integrative properties of radial oblique dendrites in hippocampal CA1 pyramidal neurons. Neuron 50, 291-307. doi: 10.1016/j.neuron.2006.03.016

Losonczy, A., Makara, J. K., and Magee, J. C. (2008). Compartmentalized dendritic plasticity and input feature storage in neurons. Nature 452, 436-441. doi: 10.1038/nature06725

Magee, J. C., and Johnston, D. (1997). A synaptically controlled, associative signal for Hebbian plasticity in hippocampal neurons. Science 275, 209-213. doi: 10.1126/science.275.5297.209

Major, G., Larkum, M. E., and Schiller, J. (2013). Active properties of neocortical pyramidal neuron dendrites. Annu. Rev. Neurosci. 36, 1-24. doi: 10.1146/annurev-neuro-062111-150343

Manita, S., Suzuki, T., Homma, C., Matsumoto, T., Odagawa, M., Yamada, K., et al. (2015). A top-down cortical circuit for accurate sensory perception. Neuron 86, 1304-1316. doi: 10.1016/j.neuron.2015.05.006

Meyer, K. (2011). Primary sensory cortices, top-down projections and conscious experience. Prog. Neurobiol. 94, 408-417. doi: 10.1016/j.pneurobio.2011.05.010

Milojkovic, B. A., Radojicic, M. S., Goldman-Rakic, P. S., and Antic, S. D. (2004). Burst generation in rat pyramidal neurones by regenerative potentials elicited in a restricted part of the basilar dendritic tree. J. Physiol. 558, 193-211. doi: 10.1113/jphysiol.2004.061416

Moser, E. I., Kropff, E., and Moser, M.-B. (2008). Place cells, grid cells, and the brain's spatial representation system. Annu. Rev. Neurosci. 31, 69-89. doi: 10.1146/annurev.neuro.31.061307.090723

Murayama, M., and Larkum, M. E. (2009). Enhanced dendritic activity in awake rats. Proc. Natl. Acad. Sci. U S A 106, 20482-20486. doi: 10.1073/pnas. 0910379106

Murayama, M., Pérez-Garci, E., Nevian, T., Bock, T., Senn, W., and Larkum, M. E. (2009). Dendritic encoding of sensory stimuli controlled by deep cortical interneurons. Nature 457, 1137-1141. doi: 10.1038/nature07663

Nevian, T., Larkum, M. E., Polsky, A., and Schiller, J. (2007). Properties of basal dendrites of layer 5 pyramidal neurons: a direct patch-clamp recording study. Nat. Neurosci. 10, 206-214. doi: 10.1038/nn1826

Palmer, L., Murayama, M., and Larkum, M. (2016). "Dendritic integration in vivo," in Dendrites, eds G. Stuart, N. Spruston, and M. Häusser (Oxford: Oxford University Press), 399-428.

Palmer, L. M., Schulz, J. M., Murphy, S. C., Ledergerber, D., Murayama, M., and Larkum, M. E. (2012). The cellular basis of $\mathrm{GABA}_{\mathrm{B}}$-mediated interhemispheric inhibition. Science 335, 989-993. doi: 10.1126/science.1217276

Palmer, L. M., Shai, A. S., Reeve, J. E., Anderson, H. L., Paulsen, O., and Larkum, M. E. (2014). NMDA spikes enhance action potential generation during sensory input. Nat. Neurosci. 17, 383-390. doi: 10.1038/nn. 3646

Pérez-Garci, E., Gassmann, M., Bettler, B., and Larkum, M. E. (2006). The $\mathrm{GABA}_{\mathrm{B} 1 \mathrm{~b}}$ isoform mediates long-lasting inhibition of dendritic $\mathrm{Ca}^{2+}$ spikes in layer 5 somatosensory pyramidal neurons. Neuron 50, 603-616. doi: 10.1016/j. neuron.2006.04.019

Poirazi, P., and Mel, B. W. (2000). Impact of active dendrites and structural plasticity on the memory capacity of neural tissue. Neuron 29, 779-796. doi: 10.1016/s0896-6273(01)00252-5

Polsky, A., Mel, B. W., and Schiller, J. (2004). Computational subunits in thin dendrites of pyramidal cells. Nat. Neurosci. 7, 621-627. doi: 10.1038/ nn1253

Polsky, A., Mel, B., and Schiller, J. (2009). Encoding and decoding bursts by NMDA spikes in basal dendrites of layer 5 pyramidal neurons. J. Neurosci. 29, 11891-11903. doi: 10.1523/JNEUROSCI.5250-08.2009 
Powers, A. R., Kelley, M., and Corlett, P. R. (2016). Hallucinations as top-down effects on perception. Biol. Psychiatry Cogn. Neurosci. Neuroimaging 1, 393-400. doi: 10.1016/j.bpsc.2016.04.003

Rockland, K. S., and Virga, A. (1989). Terminal arbors of individual "Feedback" axons projecting from area $\mathrm{V} 2$ to $\mathrm{V} 1$ in the macaque monkey: a study using immunohistochemistry of anterogradely transported Phaseolus vulgaris-leucoagglutinin. J. Comp. Neurol. 285, 54-72. doi: 10.1016/03064522(89)90075-4

Sato, M., Kawano, M., Ohkura, M., Gengyo-Ando, K., Nakai, J., and Hayashi, Y. (2015). Generation and imaging of transgenic mice that express G-CaMP7 under a tetracycline response element. PLoS One 10:e125354. doi: 10.1371/journal.pone.0125354

Schiller, J., Schiller, Y., Stuart, G., and Sakmann, B. (1997). Calcium action potentials restricted to distal apical dendrites of rat neocortical pyramidal neurons. J. Physiol. 505, 605-616. doi: 10.1111/j.1469-7793.1997.605ba.x

Shai, A. S., Anastassiou, C. A., Larkum, M. E., and Koch, C. (2015). Physiology of layer 5 pyramidal neurons in mouse primary visual cortex: coincidence detection through bursting. PLoS Comput. Biol. 11:e1004090. doi: 10.1371 /journal.pcbi. 1004090

Sheffield, M. E., and Dombeck, D. A. (2015). Calcium transient prevalence across the dendritic arbour predicts place field properties. Nature 517, 200-204. doi: 10.1038/nature13871

Sjöström, P. J., Rancz, E. A., Roth, A., and Häusser, M. (2008). Dendritic excitability and synaptic plasticity. Physiol. Rev. 88, 769-840. doi: 10.1152/physrev.00016.2007

Smith, S. L., Smith, I. T., Branco, T., and Häusser, M. (2013). Dendritic spikes enhance stimulus selectivity in cortical neurons in vivo. Nature 503, 115-120. doi: $10.1038 /$ nature 12600

Spencer, W. A., and Kandel, E. R. (1961). Electrophysiology of hippocampal neurons: IV. fast prepotentials. J. Neurophysiol. 24, 272-285.

Spruston, N. (2008). Pyramidal neurons: dendritic structure and synaptic integration. Nat. Rev. Neurosci. 9, 206-221. doi: 10.1038/nrn2286

Spruston, N., Schiller, Y., Stuart, G., and Sakmann, B. (1995). Activity-dependent action potential invasion and calcium influx into hippocampal CA1 dendrites. Science 268, 297-300. doi: 10.1126/science.7716524

Stuart, G. J., and Sakmann, B. (1994). Active propagation of somatic action potentials into neocortical pyramidal cell dendrites. Nature 367, 69-72. doi: 10.1038/367069a0

Stuart, G., Schiller, J., and Sakmann, B. (1997). Action potential initiation and propagation in rat neocortical pyramidal neurons. J. Physiol. 505, 617-632. doi: 10.1111/j.1469-7793.1997.617ba.x

Stuart, G. J., and Spruston, N. (2015). Dendritic integration: 60 years of progress. Nat. Neurosci. 18, 1713-1721. doi: 10.1038/nn.4157
Stuart, G. J., Dodt, H. U., and Sakmann, B. (1993). Patch-clamp recordings from the soma and dendrites of neurons in brain slices using infrared video microscopy. Pflugers Arch. 423, 511-518. doi: 10.1007/bf003 74949

Supèr, H., Spekreijse, H., and Lamme, V. A. F. (2001). Two distinct modes of sensory processing observed in monkey primary visual cortex (V1). Nat. Neurosci. 4, 304-310. doi: 10.1038/85170

Takahashi, H., and Magee, J. C. (2009). Pathway interactions and synaptic plasticity in the dendritic tuft regions of CA1 pyramidal neurons. Neuron 62 , 102-111. doi: 10.1016/j.neuron.2009.03.007

Takahashi, N., Oertner, T. G., Hegemann, P., and Larkum, M. E. (2016). Active cortical dendrites modulate perception. Science 354, 1587-1590. doi: 10.1126/science.aah6066

Takaya, S., Matsumoto, R., Namiki, C., Kiyosu, H., Isono, O., Hashikawa, K., et al. (2005). Frontal nonconvulsive status epilepticus manifesting somatic hallucinations. J. Neurol Sci. 234, 25-29. doi: 10.1016/j.jns.2005. 02.014

Terzuolo, C. A., and Araki, T. (1961). An analysis of intra- versus extracellular potential changes associated with activity of single spinal motoneurons. Ann. N. Y. Acad. Sci. 94, 547-558. doi: 10.1111/j.1749-6632.1961. tb35558.x

Wilson, D. E., Whitney, D. E., Scholl, B., and Fitzpatrick, D. (2016). Orientation selectivity and the functional clustering of synaptic inputs in primary visual cortex. Nat. Neurosci. 19, 1003-1009. doi: 10.1038/nn.4323

Wong, R. K., Prince, D. A., and Basbaum, A. I. (1979). Intradendritic recordings from hippocampal neurons. Proc. Natl. Acad. Sci. U S A 76, 986-990. doi: 10.1073/pnas.76.2.986

Xu, N.-L., Harnett, M. T., Williams, S. R., Huber, D., O’Connor, D. H., Svoboda, K., et al. (2012). Nonlinear dendritic integration of sensory and motor input during an active sensing task. Nature 492, 247-251. doi: 10.1038/nature 11601

Conflict of Interest Statement: The authors declare that the research was conducted in the absence of any commercial or financial relationships that could be construed as a potential conflict of interest.

Copyright (c) 2017 Manita, Miyakawa, Kitamura and Murayama. This is an open-access article distributed under the terms of the Creative Commons Attribution License (CC BY). The use, distribution and reproduction in other forums is permitted, provided the original author(s) or licensor are credited and that the original publication in this journal is cited, in accordance with accepted academic practice. No use, distribution or reproduction is permitted which does not comply with these terms. 